\title{
Extractable Zinc in Particle Size Fractions of Soils from Western Australia and Queensland
}

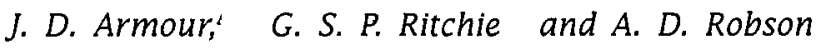

\begin{abstract}
The zinc $(\mathrm{Zn})$ content of particle size fractions of 12 mainly $\mathrm{Zn}$ deficient soils was measured by extraction with three contrasting extractants. The soils, which ranged from sands to a black earth, were from Western Australia and Queensland and particle size fractions (clay, silt, fine sand, coarse sand) were obtained by sieving and sedimentation after ultrasonification of soil suspended in deionized water. The extractants were concentrated $\mathrm{HNO}_{3} / \mathrm{H}_{2} \mathrm{SO}_{4} / \mathrm{HClO}_{4}$ (acid extractable or AE- $\mathrm{Zn}$ ), DTPA and $0.002 \mathrm{M} \mathrm{CaCl}_{2}$. For each extractant, $\mathrm{Zn}$ contents of the fractions and whole soils were correlated with organic carbon and ammonium oxalate extractable $\mathrm{Fe}$ and $\mathrm{Al}$.

The AE-Zn concentrations in whole soils were $0.6-132 \mathrm{mg} \mathrm{kg}^{-1}$ and high clay soils had higher concentrations (mean $54 \mathrm{mg} \mathrm{kg}^{-1}$ ) than low clay soils (mean $2 \mathrm{mg} \mathrm{kg}^{-1}$ ). After fractionation, lowest AE- and DTPA-Zn were found in coarse sand fractions and concentrations increased with decreasing particle size. Clay plus silt fractions contained 60-99\% of the whole soil $\mathrm{AE}-\mathrm{Zn}$ and $76-93 \%$ of the whole soil DTPA- $\mathrm{Zn}$. The $\mathrm{CaCl}_{2}-\mathrm{Zn}$ concentrations were very low $\left(<5.0 \mu \mathrm{g} \mathrm{kg}^{-1}\right)$ for all soils. In whole soils, DTPA-Zn was only a small proportion, $3 \cdot 2 \%$ and $1 \cdot 8 \%$, of the $\mathrm{AE}-\mathrm{Zn}$ in the low clay and high clay soils, respectively. The $\mathrm{CaCl}_{2}-\mathrm{Zn}$ was generally less than $2 \%$ of the DTPA-Zn in whole soils.

In whole soils, $\mathrm{AE}-\mathrm{Zn}$ was correlated with oxalate extractable $\mathrm{Fe}$ and with oxalate $\mathrm{Al}$ $(r=0.72$ and 0.71 , respectively; $P<0.01)$, whereas DTPA-Zn was correlated with oxalate extractable Fe $(r=0.82 ; P<0.01)$. The AE- and DTPA-Zn were correlated with organic carbon only in some fractions. The DTPA- and $\mathrm{CaCl}_{2}-\mathrm{Zn}$ were not correlated with $\mathrm{AE}-\mathrm{Zn}$ content, nor was DPTA-Zn correlated with $\mathrm{CaCl}_{2}-\mathrm{Zn}$ in whole soils or fractions $(P<0.05)$.

Dispersion of the soils with ultrasonification in the absence of dispersing agents was not as effective as dispersion with conventional mechanical/chemical dispersion. The percentage of the soil recovered in the clay fraction after sonification was $23-78 \%$ of that recovered by the conventional method. Fine and coarse sand contents were similar for either method, indicating that incomplete dispersion of clay by ultrasonification resulted in higher silt contents.
\end{abstract}

\section{Introduction}

Most of the zinc $(\mathrm{Zn})$ in soils is on surfaces of clays, hydrous oxides and organic matter, rather than in solution. Zn deficiency in plants is caused either by inherently low concentrations in the soil or because reactions with soil components make $\mathrm{Zn}$ unavailable to plants. Reactions of $\mathrm{Zn}$ with individual components of the soil are reasonably well documented (e.g. Ghanem and Mikkelsen 1988), but the relative importance of the components in controlling $\mathrm{Zn}$ availability is not clear. The soil components that react with $\mathrm{Zn}$ can be 
present in different forms which may be distinguished according to their size. For example, iron oxides may occur as discrete particles in the clay size fraction or as coatings on larger grains. Organic matter may be present in the sand size fraction binding small particles together, or as discrete, finer particles. In both cases, it is not known if $\mathrm{Zn}$ reacts with each form of the soil constituent in a similar manner or to an equivalent extent. Both these considerations are important for assessing the availability of $\mathrm{Zn}$ to plants.

$\mathrm{Zn}$ in soils may be divided into unavailable ( $\mathrm{Zn}$ released by soil surfaces too slowly to provide an adequate source for plants), potentially available ( $\mathrm{Zn}$ released by soil surfaces) and readily available $\mathrm{Zn}$ ( $\mathrm{Zn}$ in the soil solution). The total amount of $\mathrm{Zn}$ in a soil is measured by extraction with concentrated acids, while chelating agents such as DTPA are reported to measure potentially available $\mathrm{Zn}$ (Lindsay and Norvell 1978). Readily available $\mathrm{Zn}$ can be measured by extraction of the soil solution, but the use of dilute $\mathrm{CaCl}_{2}$ has many analytical advantages. Across a range of soil types, it may be necessary to measure a combination of intensity and quantity to predict the response of plants to $\mathrm{Zn}$ fertilizer because of the failure of quantity tests alone (Tiller et al. 1972; McGrath et al. 1985).

We do not know if unavailable $\mathrm{Zn}$ tends to be associated with a certain size fraction and/or represents a higher proportion of total $\mathrm{Zn}$ than other forms. Similarly, we do not know if potentially available $\mathrm{Zn}$ comes mainly from one size fraction because it accumulates there, or because it accumulates to an equal extent in all size fractions but is not equally extractable from them. The source of available $\mathrm{Zn}$ may also be elucidated by knowing the size fraction from which readily available $\mathrm{Zn}$ is most easily replenished.

After dispersal of 15 soils from the United States with an ultrasonic probe and separation of fractions, Khan (1979) found that concentations of DTPA extractable $\mathrm{Zn}$ were generally highest in clay and lowest in sand fractions. Distribution of $\mathrm{Zn}$ among particle size fractions has not been reported for Australian soils. The objective of our research was to establish with which size fractions $\mathrm{Zn}$ was associated, the chemical extractability of the $\mathrm{Zn}$ in each fraction and whether $\mathrm{Zn}$ extracted by the same solution was equally extractable from different size fractions. We fractionated soils with a wide range of $\mathrm{pH}$ and clay contents into different size fractions by sonification and then extracted the fractions with concentrated acids, DTPA and $\mathrm{CaCl}_{2}$.

\section{Materials and Methods}

Twelve surface $(0-10 \mathrm{~cm}$ ) soils that were mainly $\mathrm{Zn}$ deficient (Armour et al, in preparation) were collected from Western Australia and Queensland and separated into clay, silt, sand and coarse sand fractions. The soils were sieved to $<2 \mathrm{~mm}$ and ranged from sand to sandy clay loam (W.A.) and clay loam to clay (QId; Tables 1 and 2). Acid extractableZn, DTPA-Zn and $\mathrm{CaCl}_{2}-\mathrm{Zn}$ were measured in the whole soil and fractions.

\section{Particle Size Separation}

Particle size separation was achieved by ultrasonification [essentially the procedure of Khan (1979), a modification of the method of Genrich and Bremner (1974)] and also by a conventional chemical/mechanical dispersion method for comparison. 
Table 1. Some soil properties $(0-10 \mathrm{~cm}$, air-dry basis)

\begin{tabular}{|c|c|c|c|c|c|c|c|c|c|}
\hline Soil & Location & $\begin{array}{c}\text { Soil } \\
\text { classification }^{\mathrm{A}}\end{array}$ & $\begin{array}{c}\mathrm{pH} \\
\left(1: 5 \mathrm{H}_{2} \mathrm{O}\right)\end{array}$ & $\begin{array}{l}O C^{B} \\
(\%)\end{array}$ & $\begin{array}{c}\mathrm{AE}-\mathrm{Zn}^{\mathrm{C}} \\
\left(\mathrm{mg} \mathrm{kg} \mathrm{kg}^{-1}\right)\end{array}$ & $\begin{array}{c}\text { DTPA-Zn } \\
\left(\mathrm{mg} \mathrm{kg}^{-1}\right)\end{array}$ & $\begin{array}{l}\mathrm{CaCl}_{2}-\mathrm{Zn} \\
\left(\mu \mathrm{g} \mathrm{kg}^{-1}\right)\end{array}$ & $\begin{array}{l}\mathrm{Fe}^{\mathrm{D}} \\
(\%)\end{array}$ & $\begin{array}{l}\mathrm{Al}^{\mathrm{D}} \\
(\%)\end{array}$ \\
\hline \multicolumn{10}{|c|}{ Western Australia } \\
\hline 1 & Swan Coastal Plain & Uc $2 \cdot 33$ & $5 \cdot 3$ & $2 \cdot 99$ & $0 \cdot 6$ & 0.03 & $1 \cdot 3$ & $<0.01$ & $<0.01$ \\
\hline 2 & Wongan Hills & Uc $5 \cdot 22$ & $6 \cdot 2$ & $0 \cdot 50$ & $1-9$ & 0.05 & $5 \cdot 0$ & 0.02 & 0.02 \\
\hline 3 & Bramley. & Dy $3 \cdot 61$ & $7 \cdot 4$ & $0 \cdot 92$ & $1 \cdot 4$ & 0.06 & $1 \cdot 3$ & $0 \cdot 01$ & $0 \cdot 12$ \\
\hline 4 & Talbot & Dy 3.81 & $6 \cdot 5$ & $3 \cdot 04$ & $7 \cdot 1$ & 0.04 & $<0 \cdot 5$ & 0.05 & 0.43 \\
\hline 5 & Dandaragan & Uc $5 \cdot 21$ & $6 \cdot 8$ & 0.47 & $1 \cdot 4$ & 0.05 & $0 \cdot 5$ & 0.02 & 0.02 \\
\hline 6 & Merredin & $\operatorname{Dr} 2 \cdot 33$ & $6 \cdot 9$ & $1 \cdot 56$ & $10 \cdot 1$ & $0 \cdot 66$ & $3 \cdot 5$ & 0.03 & 0.06 \\
\hline \multicolumn{10}{|c|}{ Queensland } \\
\hline 7 & Murray Upper & $\mathrm{Gn} 2 \cdot 21$ & $6 \cdot 1$ & $1 \cdot 92$ & $40-4$ & 0.50 & $4-0$ & $0 \cdot 23$ & $0 \cdot 12$ \\
\hline 8 & Walkamin & Gn $3 \cdot 11$ & $6 \cdot 3$ & $2 \cdot 84$ & $73 \cdot 7$ & $1 \cdot 56$ & $4 \cdot 5$ & 0.68 & $0 \cdot 20$ \\
\hline 9 & Tolga & $\mathrm{Gn} 3 \cdot 14$ & $5 \cdot 6$ & $1 \cdot 72$ & $132 \cdot 0$ & $0 \cdot 18$ & $4 \cdot 0$ & $0 \cdot 31$ & 0.62 \\
\hline 10 & Kingaroy & $\mathrm{Gn} 3 \cdot 74$ & $5 \cdot 7$ & $2 \cdot 11$ & $18 \cdot 2$ & 0.16 & $1 \cdot 3$ & $0 \cdot 18$ & 0.21 \\
\hline 11 & Emerald & Uf $6 \cdot 33$ & $7 \cdot 4$ & 0.57 & $58 \cdot 3$ & 0.68 & $<0.5$ & $0 \cdot 17$ & 0.23 \\
\hline 12 & Miles & $\operatorname{Ug} 5 \cdot 24$ & $8 \cdot 0$ & $1 \cdot 01$ & $48 \cdot 0$ & $0 \cdot 26$ & $3 \cdot 0$ & 0.13 & 0.11 \\
\hline
\end{tabular}

A Northcote (1971).

B Organic carbon.

C Acid extractablezn.

D Acid ammonium oxalate extraction. 
Table 2. Particle size distribution for ultrasonic and conventional dispersion methods

\begin{tabular}{|c|c|c|c|c|c|c|c|c|c|}
\hline \multirow[t]{2}{*}{ Soil } & \multirow[t]{2}{*}{ Texture } & \multirow{2}{*}{$\begin{array}{l}\text { Dispers. } \\
\text { method }^{\mathrm{A}}\end{array}$} & \multicolumn{7}{|c|}{ Fractions (\%) } \\
\hline & & & $<2$ & $2-20$ & $20-45$ & $2-63$ & $45-212$ & $63-212$ & $>212 \mu \mathrm{m}$ \\
\hline \multirow[t]{2}{*}{1} & sand & C & $6 \cdot 5$ & $2 \cdot 1$ & 0.9 & & $7 \cdot 1$ & & $83 \cdot 4$ \\
\hline & & $\mathrm{U}$ & $4 \cdot 1$ & & & $3 \cdot 0$ & & $7 \cdot 1$ & $85 \cdot 9$ \\
\hline \multirow[t]{2}{*}{2} & sand & C & $7 \cdot 7$ & 0.8 & 0.5 & & $25 \cdot 0$ & & $76 \cdot 1$ \\
\hline & & $\mathrm{U}$ & $1 \cdot 8$ & & & $4 \cdot 0$ & & $14 \cdot 5$ & $79 \cdot 7$ \\
\hline \multirow[t]{2}{*}{3} & sand & C & $8 \cdot 3$ & $2 \cdot 9$ & $1 \cdot 5$ & & $16 \cdot 7$ & & $70 \cdot 6$ \\
\hline & & $U$ & $4 \cdot 5$ & & & $12 \cdot 0$ & & $16 \cdot 3$ & $67 \cdot 1$ \\
\hline \multirow[t]{2}{*}{4} & gravelly & C & $14 \cdot 8$ & $5 \cdot 9$ & $3 \cdot 0$ & & $27 \cdot 1$ & & $49 \cdot 2$ \\
\hline & sandy loam & $U$ & $6 \cdot 1$ & & & $16 \cdot 0$ & & $25 \cdot 4$ & $52 \cdot 5$ \\
\hline \multirow[t]{2}{*}{5} & sandy & C & $9 \cdot 4$ & $1 \cdot 1$ & $0 \cdot 7$ & & $11 \cdot 3$ & & $77 \cdot 6$ \\
\hline & loam & $\mathrm{U}$ & $2 \cdot 9$ & & & $5 \cdot 3$ & & $8 \cdot 6$ & $83 \cdot 2$ \\
\hline \multirow[t]{2}{*}{6} & sandy clay & C & $21 \cdot 0$ & $6 \cdot 9$ & $3 \cdot 5$ & & $20 \cdot 7$ & & $47 \cdot 9$ \\
\hline & loam & $\mathrm{U}$ & $10 \cdot 8$ & & & $19 \cdot 7$ & & $19 \cdot 7$ & $49 \cdot 8$ \\
\hline \multirow[t]{2}{*}{7} & clay & C & $24 \cdot 7$ & $21 \cdot 0$ & $9 \cdot 3$ & & $13 \cdot 4$ & & $31 \cdot 6$ \\
\hline & loam & $\mathrm{U}$ & $14 \cdot 3$ & & & $43 \cdot 4$ & & $11 \cdot 7$ & $30 \cdot 6$ \\
\hline \multirow[t]{2}{*}{8} & clay & C & $48 \cdot 2$ & $21 \cdot 1$ & $4 \cdot 7$ & & $7 \cdot 6$ & & $18 \cdot 3$ \\
\hline & & $\mathrm{U}$ & $22 \cdot 7$ & & & $42 \cdot 4$ & & $9 \cdot 4$ & $25 \cdot 3$ \\
\hline \multirow[t]{2}{*}{9} & clay & C & $60 \cdot 9$ & $16 \cdot 2$ & $4 \cdot 1$ & & $12 \cdot 2$ & & 6.6 \\
\hline & & U & $37 \cdot 2$ & & & $42 \cdot 4$ & & $13 \cdot 2$ & $7 \cdot 2$ \\
\hline \multirow[t]{2}{*}{10} & clay & $C$ & $30 \cdot 0$ & $19 \cdot 4$ & $7 \cdot 9$ & & $15 \cdot 1$ & & $27 \cdot 7$ \\
\hline & & U & $16 \cdot 9$ & & & $38 \cdot 1$ & & $14 \cdot 3$ & $30 \cdot 1$ \\
\hline \multirow[t]{2}{*}{11} & clay & $C$ & 65.0 & $15 \cdot 8$ & $5 \cdot 6$ & & $9 \cdot 1$ & & $4 \cdot 4$ \\
\hline & & $\mathrm{U}$ & $50 \cdot 9$ & & & $23 \cdot 0$ & & $16 \cdot 0$ & $10 \cdot 0$ \\
\hline \multirow[t]{2}{*}{12} & clay & $C$ & $47 \cdot 6$ & 17.9 & $5 \cdot 3$ & & $13 \cdot 7$ & & $15 \cdot 4$ \\
\hline & & $\mathrm{U}$ & $36 \cdot 4$ & & & $34 \cdot 1$ & & $13 \cdot 3$ & $16 \cdot 2$ \\
\hline
\end{tabular}

A $C$, chemical dispersion; U, ultrasonic dispersion.

Size limits for the fractions from sonification (chosen for convenience of separation) were clay $(<2 \mu \mathrm{m})$, silt $(2-63 \mu \mathrm{m})$, fine sand $(63-212 \mu \mathrm{m})$ and coarse sand $(212-2000 \mu \mathrm{m})$. Soils were dispersed with a Braunsonic 1510 ultrasound at full power $(300 \mathrm{~W})$ for $15 \mathrm{~min}$. A stirred suspension of $50 \mathrm{~g}$ soil $200 \mathrm{ml}^{-1}$ deionized water was cooled with a water jacket $<20^{\circ} \mathrm{C}$ during sonification. To minimize the potential for re-aggregation of dispersed material, the suspensions were washed through a $63 \mu \mathrm{m}$ stainless steel sieve immediately after sonification until the filtrate was clear. The sieve contents $(>63 \mu \mathrm{m})$ were washed with a minimum of deionized water into containers and the excess water was removed after sedimentation. The washing of the size fractions with water would not have caused much disturbance of the equilibrium of $\mathrm{Zn}$ between the solution and surfaces because the majority of $\mathrm{Zn}$ in soils is strongly held at specific adsorption sites. After oven-drying at $40^{\circ} \mathrm{C}$, the sand was sieved through a $212 \mu \mathrm{m}$ stainless steel sieve. Material passing through the sieve was fine sand $(63-212 \mu \mathrm{m})$, while coarse sand $(>212 \mu \mathrm{m})$ was retained on the sieve.

Clay and silt were separated by centrifugation (Khan 1979) within $24 \mathrm{~h}$ of dispersion. In our method, we concentrated the clay by centrifugation at a relative centrifugal force of 2600 (rather than by the use of filter candles) for $30 \mathrm{~min}$ and removed the supernatant by vacuum. This speed and time removed clay material of $<0.22 \mu \mathrm{m}$ or with a specific gravity of $<2.61 \mathrm{~g} \mathrm{~cm}^{-3}$. The sand fractions were only kept under water for the $1-2$ days required for the separation procedure. Silt and clay fractions were oven-dried at $40^{\circ} \mathrm{C}$ then gently crushed in an agate pestle and mortar.

Conventional particle size analysis was determined in duplicate by the pipette method after shaking the soil in a solution of $2.5 \%$ sodium hexametaphosphate in $0.1 \mathrm{M} \mathrm{NaOH}$ (Gee and Bauder 1986). The particle size limits for this method were <2, 2-20, 20-45, 45-212 and $212-2000 \mu \mathrm{m}$ for clay, silt, very fine sand, fine sand and coarse sand, respectively. 


\section{Soil Analyses}

The whole soil and fractions were analysed in duplicate by the methods below. All equipment used for $\mathrm{Zn}$ analyses was soaked in $0.2 \mathrm{M} \mathrm{Na}$ EDTA, rinsed in deionized water, soaked in $2 \% \mathrm{HNO}_{3}$ and rinsed with deionized water.

Total $\mathrm{Zn}$ was estimated by digestion in concentrated $\mathrm{HNO}_{3} / \mathrm{H}_{2} \mathrm{SO}_{4} / \mathrm{HClO}_{4}$ and we have termed this fraction acid extractable (AE) $\mathrm{Zn}$. This was the method of Baker and Amacher (1982), except that we omitted HF. The DTPA-Zn was determined by the method of Lindsay and Norvell (1978). The $\mathrm{Zn}$ extractable in $0.002 \mathrm{M} \mathrm{CaCl}_{2}$ was measured on extracts obtained by shaking soil at a soil/solution ratio of $1: 5$ for $16 \mathrm{~h}$. Supernatants from each extract were filtered $(<0.45 \mu \mathrm{m})$ after centrifugation and read by flame (DPTA-, AE-Zn) or graphite furnace atomic absorption $\left(\mathrm{CaCl}_{2}-\mathrm{Zn}\right.$, acidified to $0.01 \mathrm{M}$ with $\left.3 \mathrm{M} \mathrm{HCl}\right)$.

Organic carbon was determined by the method of Walkley and Black (1934) with the colorimetric finish of Sims and Haby (1971). Fe and Al were extracted with acid ammonium oxalate at a soil: solution ratio of $1: 40$ (McKeague and Day 1966) and analysed by atomic absorption (Searle and Daly 1977).

\section{Results}

\section{Particle Size Separation}

The particle size separation obtained by sonification differed from that obtained by conventional chemical/mechanical dispersion (Table 2). The percentage of the soil measured in the clay size fraction after sonification was $23-78 \%$ (mean $53 \%$ ) of that measured by the conventional dispersion method. The proportion of the $2-63 \mu \mathrm{m}$ fraction of sonified soils was generally larger than that of the $2-45 \mu \mathrm{m}$ fraction in conventionally dispersed soils, while the content of the $63-212 \mu \mathrm{m}$ fraction of sonified soils was similar to the content of the $45-212 \mu \mathrm{m}$ fraction of conventionally dispersed soils. These comparisons, and the similarity in coarse sand contents for both dispersion methods, suggest that incomplete dispersion of the clay after sonification (shown by lower clay \% in all soils) produced an increase in the $2-63 \mu \mathrm{m}$ fraction rather than in the larger size fractions.

\section{Extractable $Z n$ Concentrations in Whole Soils and Fractions}

The AE-Zn concentrations in whole soils were $0.6-132 \mathrm{mg} \mathrm{kg}^{-1}$ (Table 1). The high clay soils (sandy clay loam-clay soils, soils 6-12) had much higher concentrations (mean $54 \mathrm{mg} \mathrm{kg}^{-1}$ ) than the low clay soils (sandy-sandy loam soils, soils $1-5$, mean $2 \mathrm{mg} \mathrm{kg}^{-1}$ ).

When the soils were separated into fractions, lowest concentrations of $\mathrm{AE}-\mathrm{Zn}$ were found in coarse sand fractions and the concentration increased with decreasing particle size of the fraction (Fig. $1 a$ ). The AE-Zn concentrations in the clay and silt fractions of the high clay soils were generally much higher than in the fractions of the low clay soils. The mean percentage of whole soil $\mathrm{AE}-\mathrm{Zn}$ in the clay and silt fractions was $44 \%$ (range $20-83 \%$ ) and $36 \%$ (range 16-53\%) respectively (Fig. 1 b). Clay plus silt fractions contained between 60 and $99 \%$ of whole soil AE- $\mathrm{Zn}$. The mean value of the sum of AE- $\mathrm{Zn}$ in each fraction multiplied by the proportion of each fraction in soil was $96 \%$ of the AE-Zn of the whole soil (range 64-168\%).

The DTPA extractable $\mathrm{Zn}$ concentrations were very low in the low clay soils $\left(<0.1 \mathrm{mg} \mathrm{kg}^{-1}\right)$ and variable in the high clay soils $\left(0 \cdot 2-1.6 \mathrm{mg} \mathrm{kg}^{-1}\right.$; Table 1$)$. 

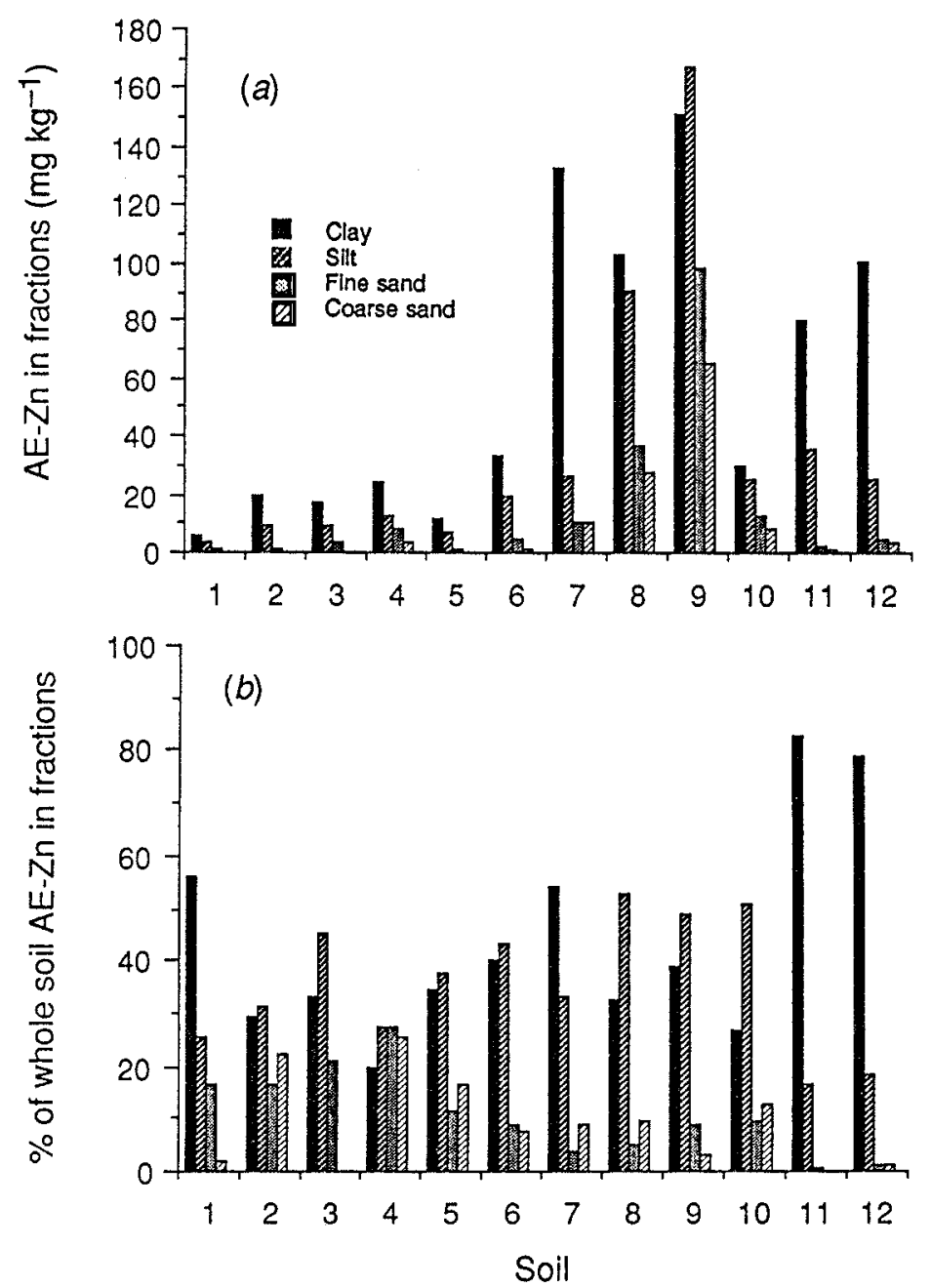

Fig. 1. Plots of $(a)$ acid extractable $Z n$ concentration in clay, silt, fine sand and coarse sand fractions (standard error of the mean is $1 \cdot 1$ ), and (b) proportion of acid extractable $\mathrm{Zn}$ in whole soils in clay, silt, fine sand and coarse sand fractions.

After fractionation, the concentration of DTPA-Zn increased with decreasing particle size of the fraction of all soils except in the north Queensland euchrozem (soil 8; Fig. 2a). In this soil, the highest $\mathrm{Zn}$ concentration was found in the fine sand. Even though there was far less DTPA-Zn in the whole low clay soils, the concentration in each size fraction was similar for the two groups of soils. Only in the coarse sand fractions were the DTPA-Zn concentrations of low clay soils consistently lower than in the high clay soils.

The percentage of whole soil DTPA-Zn found in each fraction generally increased with decreasing particle size of each fraction (Fig. $2 b$ ). An average of $49 \%$ (range $20-70 \%$ ) of the whole soil DTPA- $\mathrm{Zn}$ was found in the clay fraction and 

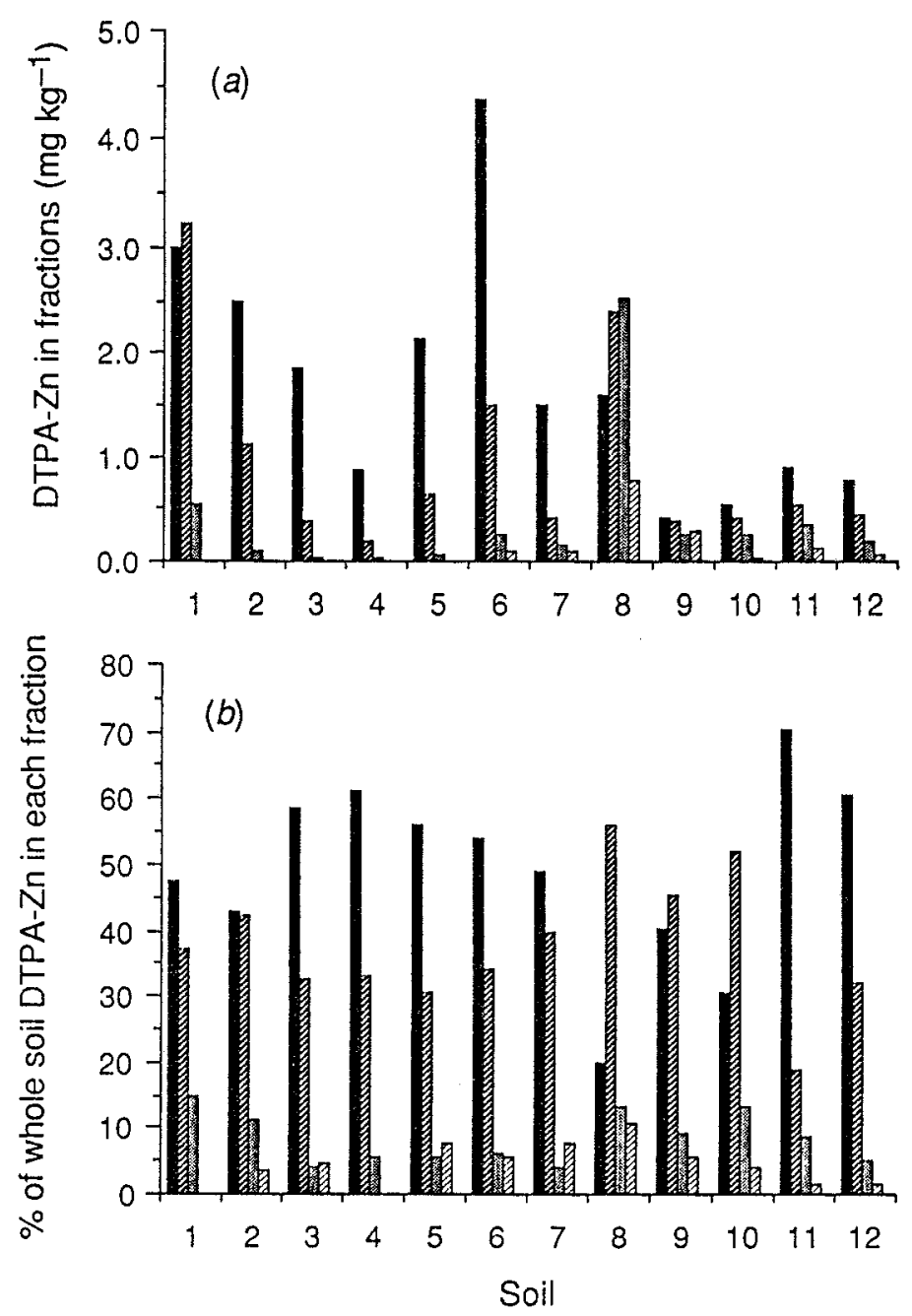

Fig. 2. Plots of (a) DTPA extractable $\mathrm{Zn}$ concentration in clay, silt, fine sand and coarse sand fractions (standard error of the mean is 0.05 ), and (b) proportion of DTPA extractable $\mathrm{Zn}$ in whole soils in clay, silt, fine sand and coarse sand fractions. (Legend as for Fig. 1.)

$38 \%$ (range 19-56\%) was in the silt fraction. Clay plus silt fractions accounted for $76-93 \%$ of the whole soil DTPA-Zn. The mean value of the sum of DTPA-Zn in each fraction multiplied by the percentage of each fraction in the soil was $246 \%$ (range $88-1030 \%$ ) of whole soil DTPA-Zn.

The proportion of AE- $\mathrm{Zn}$ extracted by DTPA was higher in the low clay soils and fractions than in the high clay soils and fractions. In whole soils, DTPA-Zn was only a small proportion, $3 \cdot 2 \%$ and $1 \cdot 8 \%$, of the AE- $\mathrm{Zn}$ in the low clay and high clay soils, respectively. In silt and in clay fractions, DTPA-Zn was approximately $20 \%$ of the AE-Zn for the low clay soils and $3 \%$ for the high clay soils, respectively. 


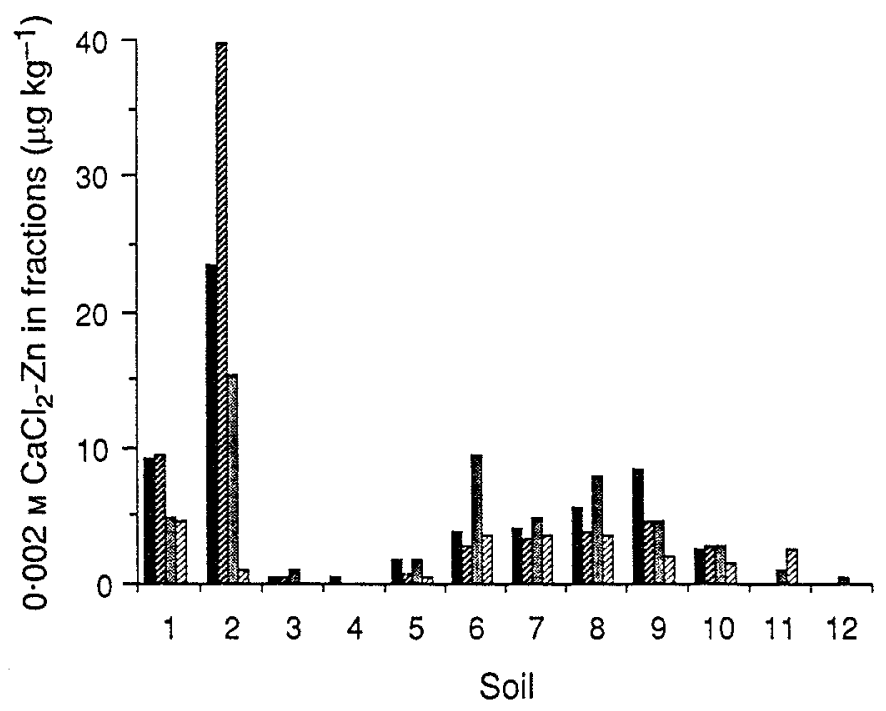

Fig. 3. The $\mathrm{CaCl}_{2}$ extractable $\mathrm{Zn}$ concentrations in clay, silt, fine sand and coarse sand fractions (standard error of the mean is 0.4 ; legend as for Fig. 1).

$\mathrm{Zn}$ extractable in $0.002 \mathrm{M} \mathrm{CaCl}_{2}$ was very low for all soils (from $<0.5$ to $4.5 \mu \mathrm{g} \mathrm{kg}^{-1}$ ) and there were no consistent trends in the distribution of $\mathrm{CaCl}_{2}-\mathrm{Zn}$ with particle size (Fig. 3). Data for the proportion of whole soil $\mathrm{CaCl}_{2}-\mathrm{Zn}$ found in each fraction was not presented because the concentration of $\mathrm{Zn}$ in some fractions and whole soils was less than $0.5 \mu \mathrm{g} \mathrm{kg} \mathrm{kg}^{-1}$ soil.

The DTPA- and $\mathrm{CaCl}_{2}-\mathrm{Zn}$ were not correlated with $\mathrm{AE}-\mathrm{Zn}$ content, nor was DTPA- $\mathrm{Zn}$ correlated with $\mathrm{CaCl}_{2}-\mathrm{Zn}$ in the fractions or the whole soil $(P>0.05)$.

\section{Correlation of Extractable Zn in Whole Soils and Size Fractions with Soil Properties}

In whole soils, $\mathrm{AE}-\mathrm{Zn}$ was correlated with oxalate extractable $\mathrm{Fe}$ and with oxalate extractable Al ( $r=0.72$ and 0.71 , respectively; $P<0.01)$. In fractions, $\mathrm{AE}-\mathrm{Zn}$ was correlated with oxalate extractable $\mathrm{Fe}$ in coarse sand fractions $(r=0.94 ; P<0.01)$ and with oxalate extractable $\mathrm{Al}$ in fine sand fractions $(r=0.92 ; P<0.01)$. The AE-Zn was correlated with organic carbon in coarse sand fractions $(r=0.95 ; P<0.01)$. The DTPA-Zn was correlated with oxalate extractable Fe $(r=0.82 ; P<0.01)$ in whole soils and after fractionation with $\mathrm{Fe}$ in fine sand $(r=0.85 ; P<0.01)$ and with Al in coarse sand fractions $(r=0.68 ; P<0.01)$. Data for ammonium oxalate extractable $\mathrm{Fe}$ and $\mathrm{Al}$ and organic carbon contents are not presented.

The $\mathrm{AE}-\mathrm{Zn}$ and $\mathrm{CaCl}_{2}-\mathrm{Zn}$ concentrations were not related to organic carbon in soils or fractions. The DTPA-Zn was correlated with organic carbon contents in silt and coarse sand fractions $(r=0.64$ and 0.70 , respectively; $P<0.05)$.

The AE- Zn in whole soil was related to \% clay plus silt by the equation

$$
y=0.8810 \times 1.0635^{x}, \quad r^{2}=0.92,
$$

where $y=\mathrm{AE}-\mathrm{Zn}$ and $x=\%$ clay plus silt. Conversely, AE-Zn decreased as the proportion of coarse and fine sand increased. 
Zn extracted by any methods was not correlated with $\mathrm{pH}$ in whole soils.

\section{Discussion}

The highest concentrations and proportions of whole soil AE- and DTPA-Zn were found in the clay and silt fractions. These results are consistent with the higher reactivity of small particles, but the $\mathrm{Zn}$ concentrations in the fractions could not be consistently related to any of the measured properties of the fractions.

As concentrations of DTPA-Zn in the soil have been related to plant growth (e.g. Lindsay and Norvell 1978), it can be considered to be an estimate of plant available $\mathrm{Zn}$, although consideration of the soil $\mathrm{pH}$ is required for acid soils (Haq and Miller 1972; Haynes and Swift 1983). These results have shown that DTPA-Zn is only a small proportion of the whole AE- $\mathrm{Zn}$ and they confirm that plant availability is related not only to the quantity in the soil but to adsorption reactions. Although there was less total $\mathrm{Zn}$ in the low clay soils than in the high clay soils, a greater proportion of the total $\mathrm{Zn}$ was extracted by DTPA. The lack of correlation of DTPA- or $\mathrm{CaCl}_{2}-\mathrm{Zn}$ with $\mathrm{AE}-\mathrm{Zn}$ suggests that unavailable $\mathrm{Zn}$ may be in a different form from available $\mathrm{Zn}$, rather than the latter being just a proportion of all forms of $\mathrm{Zn}$ which are present. Further evidence for this hypothesis may be seen in the correlation of DTPA-Zn with oxalate extractable $\mathrm{Fe}$ in contrast to the correlation of $\mathrm{AE}-\mathrm{Zn}$ with oxalate extractable $\mathrm{Fe}$ and $\mathrm{Al}$ in whole soils.

The very low concentrations of $\mathrm{CaCl}_{2}-\mathrm{Zn}$ in the whole soil are consistent with its low ionic strength, and the lack of relationship with particle size suggests that it is a true intensity measure. The low concentrations in the fractions were expected because the fractionation procedure involved suspending the fractions in large quantities of water.

After the particle size separation of the soils, the mean value of whole soil $\mathrm{AE}-\mathrm{Zn}$ calculated from the fractions was less than that measured in whole soils, while the mean of DTPA-Zn was higher. The general decrease in AE- $\mathrm{n}$ was expected because of the unavoidable loss of some fine clay and organic matter during the final centrifugation of the clay suspension and discarding of the supernatant. Soil 3 had an unusually high calculated AE-Zn of $168 \%$ (for $\mathrm{AE}-\mathrm{Zn}$ from fractions as a percentage of whole soil $\mathrm{AE}-\mathrm{Zn}$ ) which cannot be explained. The increase in availability of DTPA-Zn may be due to the exposure of fresh surfaces during sonification, either due to disintegration of organic matter or of clay particles. Soil 1 , a peaty sand, had a whole soil DTPA-Zn of $0.03 \mathrm{mg} \mathrm{kg}^{-1}$ compared with a calculated value of $0.26 \mathrm{mg} \mathrm{kg}^{-1}$ for the sum of the fractions and this produced a very high 'recovery' of $1030 \%$. The sum of AE-Zn for the fractions of this soil was $69 \%$ of the whole soil AE-Zn and shows that contamination was not the reason for the high DTPA concentrations in the fractions. Khan (1979) suggested that the reported higher concentrations of DTPA-Zn after intense sample grinding and higher shaking speeds (Soltanpour et al. 1976) may have been due to disintegration of microaggregates.

In these soils, $49 \%$ of the whole soil DTPA-Zn was in the clay fraction and $38 \%$ was in the silt fraction. Khan (1979) also found that the highest DTPA-Zn concentrations were found in clay and silt fractions of 15 United States soils. 
However, the proportion of DTPA-Zn in these fractions was higher in the U.S. soils, as $68 \%$ of the whole soil DTPA-Zn was in the clay fraction and $22 \%$ was in the silt fraction. The DTPA-Zn concentrations were between 4 and 7 times higher than in the fractions of these soils. The differences in distribution may be due to differences in the efficiency of ultrasonic particle dispersion, although comparisons between ultrasonic and conventional dispersion were not given by Khan (1979).

Considering $\mathrm{AE}-\mathrm{Zn}$ as an estimate of total $\mathrm{Zn}$ in the soil, our results are in the ranges reported in an extensive review of $\mathrm{Zn}$ concentrations on Australian soils (Tiller 1983), except for the peaty sand (soil 1) which had a lower $\mathrm{AE}-\mathrm{Zn}$ than the range reported for deep sands. The DTPA-Zn concentrations were within the ranges reported for Australian soils (Radjagukguk et al. 1980; Standley et al. 1981; Haddad and Weir 1985).

The low clay contents obtained with ultrasonic dispersion compared with conventional mechanical/chemical dispersion differ from other published data (Genrich and Bremner 1972, 1974; Curtin et al. 1987). No other work on Australian soils has published comparisons between ultrasonic and conventional dispersion techniques in the absence of dispersion agents. Despite the differences that we have found between the two techniques, sonification is currently the best method available to disperse soils without the addition of dispersing agents.

\section{Acknowledgments}

The senior author completed this research while on Study Leave from the Queensland Department of Primary Industries. We thank $\mathrm{Mr}$ W. J. Simmons for technical advice.

\section{References}

Baker, D. E., and Amacher, M. C. (1982). Nickel, copper, zinc and cadmium. In 'Methods of Soil Analyses'. (2nd Edn.) pp. 323-35. Agronomy Monograph No. 9. (Am. Soc. Agron.: Madison.)

Curtin, D., Huang, P. M., and Rostad, H. P. W. (1987). Components and particle size distribution of soil titratable acidity. Soil Sci. Soc. Am. J. 51, 332-6.

Gee, G. W., and Bauder, J. W. (1986). Particle-size analyses. In 'Methods of Soil Analysis. Part 1. Physical and Mineralogical Methods'. (2nd Edn.) pp. 383-411. Agronomy Monograph No. 9. (Am. Soc. Agron.: Madison.)

Genrich, D. A., and Bremner, J. M. (1972). A re-evaluation of the ultrasonic vibration method of dispersing soils. Soil Sci. Soc. Am. Proc. 36, 944-7,

Genrich, D. A., and Bremner, J. M. (1974). Isolation of soil particle-size fractions. Soil Sci. Soc. Am. Proc. 38, 222-45.

Ghanem, S. A., and Mikkelsen, D. S. (1988). Sorption of zinc on iron hydrous oxides. Soil Sci. 146, $15-21$.

Haddad, K. S., and Weir, R. G. (1985). Influence of soil properties on the use of soil and plant zinc to predict zinc responsiveness in maize. Aust. J. Exp. Agric. 25, 856-62.

Haq, A. U., and Miller, M. H. (1972). Prediction of availability of soil $\mathrm{Zn}, \mathrm{Cu}$ and $\mathrm{Mn}$ using chemical extractants. Agron. J. 74, 779-82.

Haynes, R. J., and Swift, R. S. (1983). An evaluation of the use of DTPA and EDTA as extractants for micronutrients in moderately acid soils. Plant Soil 74, 111-22.

Khan, A. (1979). Distribution of DTPA-extractable Fe, $\mathrm{Zn}$ and $\mathrm{Cu}$ in soil particle-size fractions. Commun. Soil Sci. Plant Anal. 10, 1211-18.

Lindsay, W. L., and Norvell, W. A. (1978). Development of a DTPA soil test for zinc, iron, manganese and copper. Soil Sci. Soc. Am. J. 42, 421-8. 
McGrath, S. P., Sanders, J. R., and Adams, T. M. (1985). Comparison of soil solution and chemical extractants to estimate metal availability to plants. J. Sci. Food Agric. 36, 532-3. McKeague, J. A., and Day, D. H. (1966). Dithionite and oxalate extractable $\mathrm{Fe}$ and $\mathrm{Al}$ as aids in differentiating various classes of soils. Can. J. Soil Sci. 46, 13-22.

Northcote, K. H. (1971). 'A Factual Key for the Recognition of Australian Soils.' (3rd Edn.) (Rellim Technical Publications: Glenside, S.A.)

Radjagukguk, B., Edwards, D. G., and Bell, L. C. (1980). Zinc availability to young wheat plants in Darling Downs black earths. Aust. J. Agric. Res. 31, 1083-96.

Searle, P. L., and Daly, B. K. (1977). The determination of aluminium, iron, manganese and silica in acid oxalate soil extracts by flame emission and atomic absorption spectrometry. Geoderma 19, 1-10.

Sims, J. R., and Haby, V. A. (1971). Simplified colorimetric determination of soil organic matter. Soil Sci. 112, 137-41.

Soltanpour, P. N., Khan, A., and Lindsay, W. L. (1976). Factors affecting DTPA-extractable Zn, $\mathrm{Fe}, \mathrm{Mn}$ and $\mathrm{Cu}$ from soils. Commun. Soil Sci. Plant Anal. 7, 797-821.

Standley, J., Giles, J. E., and Price, G. H. (1981). Commercial soil test results from pasture areas on the wet tropical coast of Queensland. J. Aust. Inst. Agric. Sci, 47, 113-17.

Tiller, K. G. (1983). Micronutrients. In 'Soils: An Australian Viewpoint'. Ch. 25. (CSIRO: Aust. Melbourne/Academic Press: London.)

Tiller, K. G., Honeysett, J. L., and DeVries, M. P. C. (1972). Soil zinc and its uptake by plants. II. Soil chemistry in relation to predicition of availability. Aust. J. Soil Res. 10, 165-82.

Walkley, A., and Black, I. A. (1934). An examination of the Degtjareff method for determining soil organic matter, and a proposed modification of the chromic acid titration method. Soil Sci. 37, 29-38. 